\title{
Predatory behaviour of trapping fungi against srf mutants of Caenorhabditis elegans and different plant and animal parasitic nematodes
}

\author{
P. MENDOZA DE GIVES ${ }^{1,2,3 *}$ K. G. DAVIES ${ }^{1}$, S. J. CLARK ${ }^{1}$ and J. M. BEHNKE \\ ${ }^{1}$ IACR-Rothamsted, Harpenden, Herts AL5 $27 Q, U K$ \\ ${ }^{2}$ School of Biological Sciences, University of Nottingham, University Park, Nottingham NG7 2RD, UK \\ ${ }^{3}$ Centro Nacional de Investigaciones Disciplinarias en Parasitología Veterinaria, Instituto Nacional de Investigaciones \\ Forestales y Agropecuarias, Km. 11.5 Carr. Federal Cuernavaca-Cuautla, Col. Progreso, Fiutepec, Estado de Morelos, \\ México. Apdo. Postal 206, CIVAC, 62500 Morelos, México
}

(Received 30 November 1998 ; revised 23 Fanuary 1999; accepted 23 Fanuary 1999)

SUMMARY

The initial infection process of nematode-trapping fungi is based on an interaction between the trapping structure of the fungus and the surface of the nematode cuticle. A bioassay was designed to investigate the predatory response of several isolates of nematode-trapping fungi against 3 mutants of Caenorhabditis elegans (AT6, AT10 and CL261), which have been reported to differ in the reaction of their cuticle to antibodies and lectins. The bioassay was also applied to infective larvae of animal (Haemonchus contortus, Teladorsagia (Ostertagia) circumcincta and Trichostrongylus axei) and plant (Meloidogyne spp.) parasitic nematodes. Differences in trapping ability were most marked in the first $24 \mathrm{~h}$, and were density dependent. Although the isolate of Arthrobotrys responded very rapidly in the first $24 \mathrm{~h}$, Duddingtonia flagrans was generally the most effective isolate and Monacrosporium responded relatively poorly throughout all experiments. All the fungi tested trapped the $s r f$ mutants of $C$. elegans more efficiently than the wild type, and there were differences between the different srf mutants of $C$. elegans. Differences in trapping ability were also observed between different isolates of $D$. flagrans; similarly, differences in trapping behaviour were observed not only amongst the different species of plantparasitic nematodes, but also between the sheathed and exsheathed larvae of the animal-parasitic nematodes.

Key words: nematophagous fungi, Caenorhabditis elegans, surface mutants, parasitic nematodes.

\section{INTRODUCTION}

The nematode cuticle is a complex structure essential for locomotion, maintenance of morphology and protection against the environment. In parasitic nematodes the cuticle is important in the recognition process by the host immune system of animals, may have a role in the resistance response of plants, and is also a site of attachment by various hyperparasitic bacteria and fungi (Bird \& Bird, 1991). Interest in the pathogens of nematodes has become increasingly important in the search for alternative control measures to replace chemical anthelmintics and nematicides.

Fungi have long been known to be parasitic on nematodes (Barron, 1977) and are considered as potential biological control agents for plant (Kerry \& Jaffee, 1997) and animal (Wolstrup et al. 1996; Llerandi Juarez \& Mendoza de Gives, 1998; Mendoza de Gives et al. 1998) parasitic nematodes. One group of these fungi, the nematode-trapping fungi, live in soil and develop organs for the capture of nematodes which are killed and then serve as a

* Corresponding author: CENID-PAVET, INIFAP, Apdo. Postal 206, CIVAC, 62500 Morelos, México. Fax: + 52732055 44. E-mail:mendozap@inifap2.inifap. conacyt.mx source of nutrients for the fungi (Barron, 1977; Duddington, 1951). The presence of nematodes act as a stimulus, inducing the formation of capture organs in nematode-predatory fungi (BartnickiGarcia, Eren \& Pramer, 1964; Nansen et al. 1988). The trapping process is thought to involve a lectin/carbohydrate recognition system between receptors on fungal traps and specific molecules on the nematode surface (Nordbring-Hertz \& Mattiasson, 1979; Nordbring-Hertz \& Friman, 1982; Rosenzweig \& Ackroyd, 1983; Rosenzweig, Premachandran \& Pramer, 1985; Tunlid, Jansson \& Nordbring-Hertz, 1992). The external surface or cuticle of nematodes serves as a protective barrier against the environment (Politz et al. 1990; Bird \& Bird, 1991), and constitutes the first site of contact with the natural enemies of nematodes. Spores of the bacterial hyperparasite Pasteuria penetrans have been shown to exhibit inter- and intra-host specificity against plant-parasitic nematodes (Sharma \& Davies, 1996; Mendoza de Gives et al. 1999). Variation in the ability of different nematophagus fungal isolates (Mendoza de Gives et al. 1994), and species (Gonzalez Cruz, Mendoza de Gives \& Quiroz Romero, 1998), to trap animal-parasitic nematodes has also been reported; a given fungal species may 
differ in the effectiveness with which it traps different species of nematodes (Nansen et al. 1988). Antigenic differences in the cuticle surface between different stages of animal and plant-parasitic nematodes are well recognized (Philipp, Parkhouse \& Ogilvie, 1980; Maizels, Meghji \& Ogilvie, 1983; Davies \& Danks, 1992; Raleigh \& Meeusen, 1996) and may well be important in the susceptibility of the nematode to trapping by predatory fungi.

Caenorhabditis elegans is a free-living nematode with a fast rate of reproduction which is easily cultured in vitro and is therefore a useful laboratory model (Wood, 1988). The production of strains of $C$. elegans with cuticles with different surface properties (svf mutants) makes it particularly suitable as a research tool for the study of the nematode cuticle (Link et al. 1992; Politz \& Philipp, 1992). Among the various mutant strains of $C$. elegans which have been developed, some exhibit altered surface binding by the lectins wheat germ agglutinin (WGA, recognizing $\quad N$-acetyl-glucosamine) and soybean agglutinin (SBA, recognizing $N$-acetyl-galactosamine). Whereas wild-type nematodes bind WGA weakly, and only at the male copulatory bursa and the hermaphrodite vulva, these surface mutants show binding over the whole cuticle (Politz et al. 1990; Link et al. 1992; Silverman, Blaxter \& Link, 1997). The cuticle of the mutant strains appears to have undergone molecular structural changes exposing molecules hidden in the wild-type, thereby altering their properties. However, in other respects, these surface mutant strains of $C$. elegans are not different from wild-type nematodes.

Quantitative, comparative studies of the interactions between nematodes which differ in their cuticular surface properties and nematode-trapping fungi provide a route to a better understanding of the interactions involved. In this paper C. elegans is used as a model in a bioassay to investigate the trapping efficacy of different nematophagous fungi against wild-type and surface mutants of C. elegans, as well as plant and animal-parasitic nematodes. We first describe experiments which established the optimum conditions for monitoring quantitatively the capture of $C$. elegans (wild type) by 4 isolates of nematophagous fungi and then, under those optimal conditions, we used surface mutants of $C$. elegans to test the hypothesis that molecular changes in the surface cuticular structures of the nematodes radically alter their susceptibility to capture by the fungi. We also test whether or not the sheath of the infective stages of animal-parasitic nematodes affects the ability of these fungi to trap nematodes.

\section{MATERIALS AND METHODS}

\section{Fungi}

Four predatory Hyphomycetes selected for their ability to produce adhesive 3-dimensional traps, were used; strains of Arthrobotrys sp. (FTHO-3) and Duddingtonia flagrans (F'THO-8) were both isolated from sheep faecal material in Mexico; another isolate of D. flagrans (PF) was kindly provided by $\mathrm{Dr}$ Pelloile, INRA, France; and 1 strain of Monacrosporium sp., (R6) isolated from a soil sample in $\mathrm{UK}$. Fungi were routinely subcultured on Petri dishes containing corn meal agar (CMA) at room temperature $\left(25-30^{\circ} \mathrm{C}\right)$.

\section{Nematodes}

C. elegans populations (Table 1) were maintained and produced in the laboratory, either on nematode growth medium (NGM) plates to which E. coli OP50 had been applied (Wood, 1988) or, to obtain a large quantity of nematodes, plates were supplied with $0.5 \mathrm{~g}$ of peanut butter. Before use, the nematodes were washed from the cultures by centrifugation in either M9 buffer (Wood, 1988) or sterile distilled water. Suspensions of nematodes were centrifuged and decanted 3 times to remove extraneous agar and bacteria. Experiments were done with larval stages (L1, L2 and dauer larvae); adults were excluded by using a $125 \mu \mathrm{m}$ mesh sieve which only allowed the larvae to pass through. Previous experiments had shown that oviposition and hatching of new larvae complicated enumeration (unpublished data). Nematodes were suspended in a standard volume, and the number of nematodes was calculated by counting the nematodes present in 20 aliquots of $5 \mu 1$. Populations of infective larvae of 3 different Trichostrongylids from 2 different sources were used (Table 1). These nematodes were washed in $25 \%$ sucrose, to remove contaminating detritus, and rinsed 3 times in sterile distilled water to eliminate the sucrose residues. They were finally resuspended in sterile water for use in experiments. Exsheathed larvae were obtained by adding $50 \mu \mathrm{l}$ of hydrochloric acid ( $2 \mathrm{M}$ ) to $50 \mathrm{ml}$ of a suspension of infective $3 \mathrm{rd}$-stage larvae for $20 \mathrm{sec}$ periods until the majority of larvae exsheathed, followed by rinsing 3 times in distilled water (Boisvenue et al. 1983). Root-knot nematode egg masses were collected from tomato roots routinely infected with root-knot nematodes and maintained in a glasshouse at $25^{\circ} \mathrm{C}$. Second-stage larvae were hatched from egg masses by placing them on a small tray in tap water at room temperature (Hooper, 1986). Larvae were separated, washed in M9 medium 3 times and finally, resuspended in sterile water and counted using the technique described by Fenwick (1951).

\section{Motility of srf mutants of $\mathrm{C}$. elegans}

In order to ascertain that motility of the different nematode treatments was not responsible for differences in capture a motility assay was performed. Three srf mutants of $C$. elegans and a wild type (N2) were tested in plastic Petri dishes $(6.0 \mathrm{~cm}$ 
Table 1. Nematode populations, strains, genotypes and their source

\begin{tabular}{llll}
\hline \hline Nematode & Strain & Genotype & Source* \\
\hline $\begin{array}{l}\text { Caenorhabditis } \\
\text { elegans }\end{array}$ & AT6 & srf-2 (yj262)I & Dr T. Stiernagle (CGC) \\
& AT10 & $\begin{array}{l}\text { srf-3 (yj10)IV } \\
\text { Srf-5 (ct115)X }\end{array}$ & \\
$\begin{array}{c}\text { Haemonchus } \\
\text { contortus }\end{array}$ & N2 & Wild-type & Dr E. Munn (BI) \\
$\begin{array}{c}\text { Teladorsagia } \\
\text { Ostertagia) }\end{array}$ & N.A. & N.A. & Dr R. Coop (MI) \\
$\begin{array}{c}\text { circumcincta } \\
\begin{array}{c}\text { Trichostrongylus } \\
\text { axei }\end{array}\end{array}$ & N.A & N.A. & Dr R. Coop (MI) \\
$\begin{array}{c}\text { Incognitogyne } \\
\text { arenaria }\end{array}$ & Race 2 & N.A. & NCSU \\
\hline \hline
\end{tabular}

* CGC, Caenorhabditis Genetics Center, Minnesota, USA; BI, Babraham Institute, Cambridge, UK; MI, Moredun Institute, Dundee, UK, NCSU, North Carolina State University, USA; N.A., not available.

Table 2. Average trap formation score $(n=3)$ for 4 nematophagous fungi and 2 populations of Caenorhabditis elegans on CMA plates after $24 \mathrm{~h}$ of incubation at $25{ }^{\circ} \mathrm{C}$ at different nematode densities

\begin{tabular}{|c|c|c|c|c|}
\hline \multirow[b]{3}{*}{ Fungus } & \multicolumn{4}{|c|}{ Caenorhabditis elegans* } \\
\hline & \multicolumn{2}{|l|}{$\begin{array}{l}\text { Srf mutant AT6 } \\
\text { trap production }\end{array}$} & \multicolumn{2}{|l|}{$\begin{array}{l}\text { Wild-type N2 } \\
\text { trap production }\end{array}$} \\
\hline & $\begin{array}{l}\text { Low nematode }{ }^{(a)} \\
\text { density }\end{array}$ & $\begin{array}{l}\text { High nematode }{ }^{(b)} \\
\text { density }\end{array}$ & $\begin{array}{l}\text { Low nematode }{ }^{(a)} \\
\text { density }\end{array}$ & $\begin{array}{l}\text { High nematode }{ }^{(b)} \\
\text { density }\end{array}$ \\
\hline Arthrobotrys sp. (FTHO-3) & 2 & 3 & 1 & 3 \\
\hline D. flagrans (FTHO-8) & 3 & 3 & 3 & 3 \\
\hline D. flagrans $(\mathrm{PF})$ & 3 & 3 & 3 & 3 \\
\hline Monacrosporium sp (R6) & $1 \cdot 3^{(\mathrm{c})}$ & $1^{(\mathrm{d})}$ & $1^{(\mathrm{c})}$ & $1 \cdot 3^{(\mathrm{d})}$ \\
\hline
\end{tabular}

* (L1, L2 and Dauer larvae), $1=1-20$ traps, $2=21-40$ traps, $3=>40$ traps, ${ }^{(a)} \leqslant 200$ nematodes per plate, ${ }^{(b)} \geqslant 200$ nematodes per plate, ${ }^{(\mathrm{c})} \leqslant 300$ nematodes per plate, ${ }^{(\mathrm{d})} \geqslant 300$ nematodes per plate.

diameter) containing corn meal agar with 3 replicate dishes per population of nematodes. Two concentric rings at 2 and $3 \mathrm{~cm}$ from the centre of the plates were drawn on the base using a marker pen to delimit 2 migrating areas (Area 1 and Area 2, respectively). One drop $(20 \mu \mathrm{l})$ of an aqueous suspension containing 200 larvae was deposited in the centre of each plate and then incubated at $25-30{ }^{\circ} \mathrm{C}$. The numbers of nematodes present in areas 1 and 2 were recorded at $30 \mathrm{~min}, 1 \mathrm{~h}, 2 \mathrm{~h}$ and $3 \mathrm{~h}$ after inoculation. Numbers of nematodes in each area at each time were analysed using repeated measures ANOVA (Greenhouse \& Geisser, 1959) following transformation to logarithms (base 10) after adding 1 to each count to adjust for zeros.

\section{Effect of incubation time on fungal trapping ability}

The 4 fungi previously described were grown from plugs of agar placed in the centre of $3.5 \mathrm{~cm}$ Petri dishes containing CMA and allowed to grow for 10 days at $25{ }^{\circ} \mathrm{C}$. A set of CMA plates without any fungus was used as control. Samples of $25 \mu \mathrm{l}$ of a suspension containing approximately 5000 nematodes of C. elegans wild type N2 in M9 solution were added to each Petri dish. All plates were incubated at $25^{\circ} \mathrm{C}$. Nematodes were recovered by washing and rinsing the surfaces of plates after 12, 24, 36, 48 and $60 \mathrm{~h}$ post-incubation. Each treatment was replicated 5 times. The total number of recovered nematodes was estimated by counting the number of specimens present in five $5 \mu \mathrm{l}$ aliquots using a stereomicroscope $(25$ and $40 \times)$. The percentage reduction in each nematode population by the action of the fungi (after a given incubation time) was estimated by comparing the numbers of nematodes in treated and untreated plates using the following formula:

$\%$ Reduction $=\frac{X_{c}-X_{t}}{X_{c}} \times 100$,

where: $X_{c}=$ mean number of nematodes recovered from control plates $(n=5)$, and $X_{t}=$ mean number of nematodes recovered from treated plates $(n=5)$. 
The percentage reductions for each fungus were compared at each incubation time using ANOVA.

\section{Effect of nematode density on trap formation and trapping ability}

The effect of nematode density on the trap formation and trapping ability in the different fungal isolates was assessed against $2 \mathrm{C}$. elegans strains (AT6 and N2) by adding nematodes to CMA plates (6 for each fungus/nematode combination) at densities ranging between 84 and 477. Trapped and untrapped nematodes were counted after $24 \mathrm{~h}$ at $25^{\circ} \mathrm{C}$ using a microscope $(25$ and $40 \times)$. Trap formation was scored on a 3 -point scale. The percentage of trapped nematodes was calculated for each plate, transformed to logits $\left(\log _{\mathrm{e}}(p /(1-p))\right.$, where $\left.p=(r+0 \cdot 5) /(n+1)\right)$ and plotted against the density of nematodes for that plate. The results were analysed by a parallel model regression analysis (Weisberg, 1985) using the statistical package GENSTAT 5 (Genstat 5 Committee, 1993).

Comparison of the trapping of 4 strains of $\mathrm{C}$. elegans and animal and plant-parasitic nematodes by

Arthrobotrys $s p$ and D. flagrans

The trapping ability of 2 nematode-trapping fungi isolates, Arthrobotrys sp. (FTHO-3) and D. flagrans (FTHO-8), which displayed a good record of trapping ability, were evaluated against a wild-type (N2) and 3 different srf mutants of C. elegans (AT6, AT10 and CL261). Fungi were cultured as previously described. This experiment was conducted using approximately 200 nematodes $(\min =109$, $\max =349$, mean $=203)$ per plate $(5$ replicates per treatment) and trapping was evaluated after $24 \mathrm{~h}$ at $25^{\circ} \mathrm{C}$. The experiment was repeated (4 replicates per treatment) using sheathed and exsheathed L3 larvae Trichostrongylids including Haemonchus contortus, Teladorsagia (Ostertagia) circumcincta and Trichostrongylus axei, and the plant-parasitic nematodes Meloidogyne incognita and $M$. arenaria (Table 1), which differ in the reaction of their cuticles to a polyclonal antibody (Davies \& Danks, 1992). The proportion of trapped nematodes in each case was analysed using logistic regression, accounting for overdispersion where necessary using Williams' procedure (Williams, 1982).

\section{RESULTS}

\section{Motility of srf mutants of $\mathrm{C}$. elegans}

A significant interaction between nematode population and time was observed $\left(\mathrm{F}_{5 \cdot 1,28 \cdot 4}=3 \cdot 45, P<\right.$ $0 \cdot 05)$. After $30 \mathrm{~min}$ a greater number of nematodes of the wild-type $($ mean $=1 \cdot 25, \log$ scale $)$ and the AT10 (mean $=0.90$ ) populations were found migrating from the centre compared to populations of AT6 $($ mean $=0 \cdot 40)$ and CL261 (mean $=0.45)$ which remained relatively concentrated in the middle of the plates. However, by $1 \mathrm{~h}$ after inoculation, migration of CL261 had increased substantially (mean $=1 \cdot 40)$ compared to the other populations (AT6 $=0.843$, $\mathrm{AT} 10=1 \cdot 243, \mathrm{~N} 2=1 \cdot 274)$. After $1 \mathrm{~h}$, migration continued to increase but only at a similarly low rate for each population and reached means of 0.995 , 1.306, 1.413 and 1.516 for AT6, AT10, CL261 and $\mathrm{N} 2$, respectively.

\section{Trap formation in nematophagous fungi}

There was little difference in overall trap formation by the fungi (Table 2; total scores of 58 and 55 for AT6 and N2, respectively). However, the srf mutant AT6 produced a slightly stronger response in terms of trap formation in Arthrobotrys sp. compared to the wild type at low densities $(<200$ nematodes per plate). Trap formation was not affected by the nematode population at higher nematode densities. Both isolates of D. flagrans consistently produced a large number of traps irrespective of the nematode and its density. Monacrosporium produced the least traps in all plates.

\section{Effect of incubation time on fungal trapping ability}

The predatory activity of all the fungi tested against the wild-type $C$. elegans increased with time so that by $60 \mathrm{~h}$ more than $95 \%$ were trapped when 5000 nematodes were added per plate (Table 3 ). However, differences in trapping ability were observed between the different fungi within the first $12 \mathrm{~h}\left(\mathrm{~F}_{3,16}=8 \cdot 55\right.$, $P=0.001)$. Arthrobotrys sp. had the most rapid trapping response against this nematode recording more than $77 \%$ of nematodes trapped after $12 \mathrm{~h} . D$. flagrans (PF) trapped $45 \%$ of nematodes by this time. In contrast, D. flagrans (FTHO-8) and Monacrosporium sp. had the slowest trapping responses with only $23 \%$ and $3 \%$, respectively, of nematodes being trapped within $12 \mathrm{~h}$. No statistical differences among the fungi existed after $24 \mathrm{~h}$ or 36 h, but Monacrosporium sp. was significantly less efficient after $48 \mathrm{~h}\left(\mathrm{~F}_{3,16}=5 \cdot 86, P=0 \cdot 007\right)$, whilst D. flagrans $\mathrm{PF}$ was slightly but still significantly less efficient after $60 \mathrm{~h}\left(\mathrm{~F}_{3,15}=3 \cdot 98, P=0 \cdot 029\right)$.

Trapping ability of nematode-trapping fungi against C. elegans srf mutants

The trapping percentages of Arthrobotrys FTHO-3, D. flagrans FTHO-8 and PF, and Monacrosporium sp. against the wild type and the srf mutant AT6 are shown in Fig. 1. The effect of nematode density on 
Table 3. Mean $(n=5)$ percentage reduction in the number of nematodes (Caenorhabditis elegans N2 wildtype) by action of 4 nematode-trapping fungi at $25^{\circ} \mathrm{C}$ in CMA plates after different incubation periods

(Nematode density approximately 5000 specimens per plate. Nematode population included L1, L2 and dauer larvae.)

\begin{tabular}{llllll}
\hline \hline Fungus & $\begin{array}{l}\text { Arthrobotrys sp. } \\
\text { (FTHO-3) }\end{array}$ & $\begin{array}{l}\text { D. flagrans } \\
(\text { FTHO-8) }\end{array}$ & $\begin{array}{l}\text { D. flagrans } \\
(\mathrm{PF})\end{array}$ & $\begin{array}{l}\text { Monacrosporium sp. } \\
\text { (R-6) }\end{array}$ & S.E.D.* \\
\hline Time (h) & & & & & \\
12 & $77 \cdot 3$ & $22 \cdot 7$ & $45 \cdot 3$ & $2 \cdot 9$ & $9 \cdot 03$ \\
24 & $86 \cdot 7$ & $82 \cdot 8$ & $86 \cdot 4$ & $70 \cdot 2$ & $9 \cdot 86$ \\
36 & $85 \cdot 0$ & $87 \cdot 4$ & $88 \cdot 8$ & $64 \cdot 7$ & $6 \cdot 15$ \\
48 & $97 \cdot 4$ & $93 \cdot 2$ & $96 \cdot 0$ & $74 \cdot 8$ & $1 \cdot 05$ \\
60 & $99 \cdot 2$ & $97 \cdot 4$ & $95 \cdot 8$ & $98 \cdot 4$ & \\
\hline \hline
\end{tabular}

* Standard error of the difference between means.
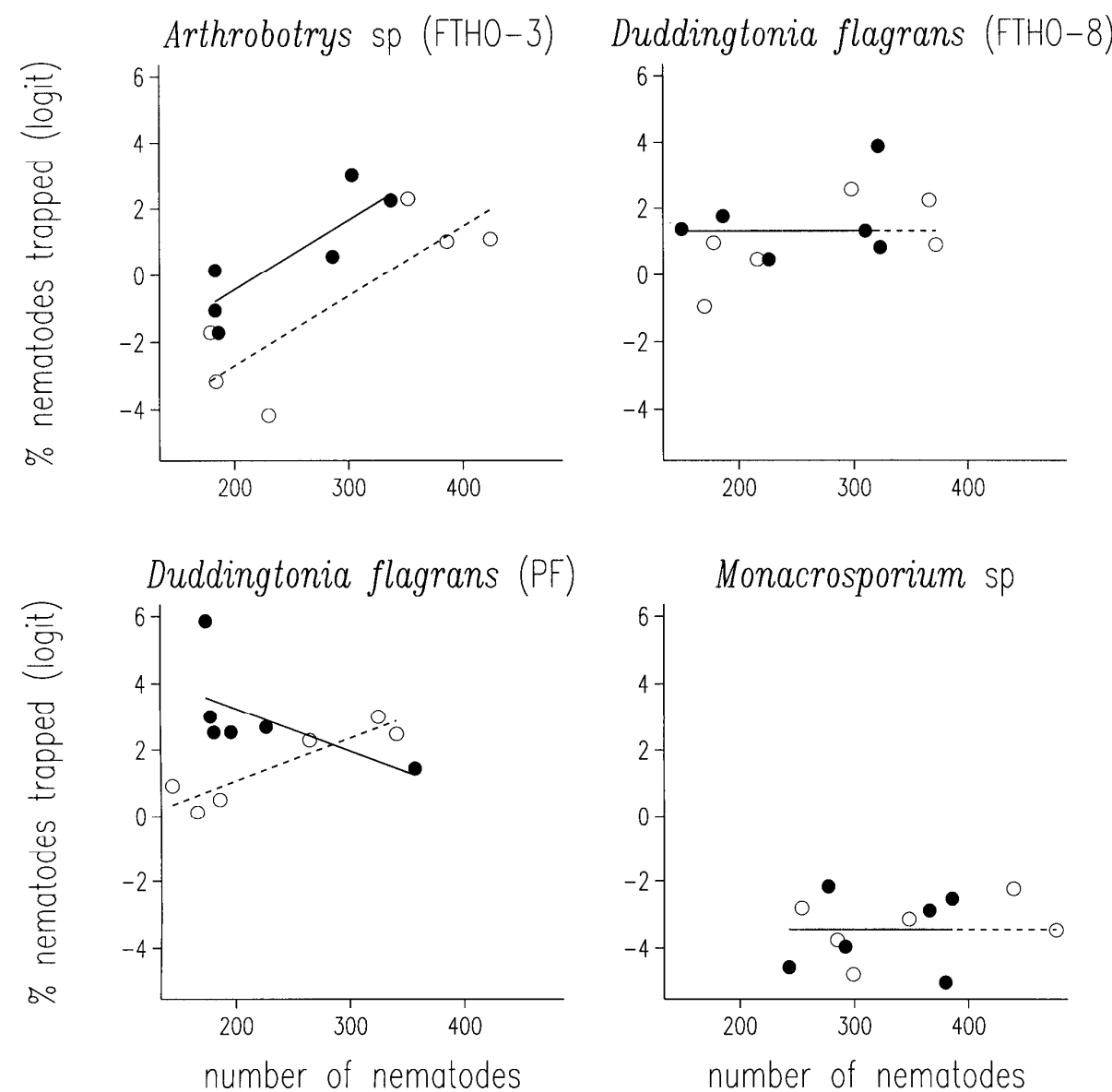

Fig. 1. Trapping proportions (after logistic transformation) of a mixture of stages (L1, L2 and dauer larvae) of 2 populations of Caenorhabditis elegans, wild-type N2 and AT6 srf mutant by 4 nematode-trapping fungi after $24 \mathrm{~h}$ on CMA plates at $25^{\circ} \mathrm{C}$ at different nematode densities. $\left(\mathrm{O}_{---} \mathrm{O}\right)$ and $(-\mathrm{O})$ Regression lines for N2 and AT6, respectively.

trapping ability was dependent on the fungal isolate and the nematode population. For example, whilst a marked increase in trapping percentage with nematode density was seen for the 2 nematodes for the Arthrobotrys isolate, overall AT6 was trapped more efficiently $\left(\mathrm{F}_{1,8}=7 \cdot 80, P=0 \cdot 023\right)$. The $D$. flagrans $\mathrm{PF}$ isolate behaved very differently against the 2 nematodes both in terms of the change in trapping percentage with density $\left(\mathrm{F}_{1,8}=9 \cdot 39, P=0.015\right)$ and the overall level of trapping $\left(\mathrm{F}_{1,8}=6 \cdot 48, P=0 \cdot 034\right)$. There was no difference in trapping of the wild-type and sif mutant of $C$. elegans by the other 2 fungi, $D$. flagrans FTHO-8 and Monacrosporium, and for neither of these fungi was there evidence of density dependence in the trapping percentage. However, these 2 fungi trapped very different percentages of nematodes overall.

Arthrobotrys sp. showed a very low activity against

\section{Смmвridge J JURALS}




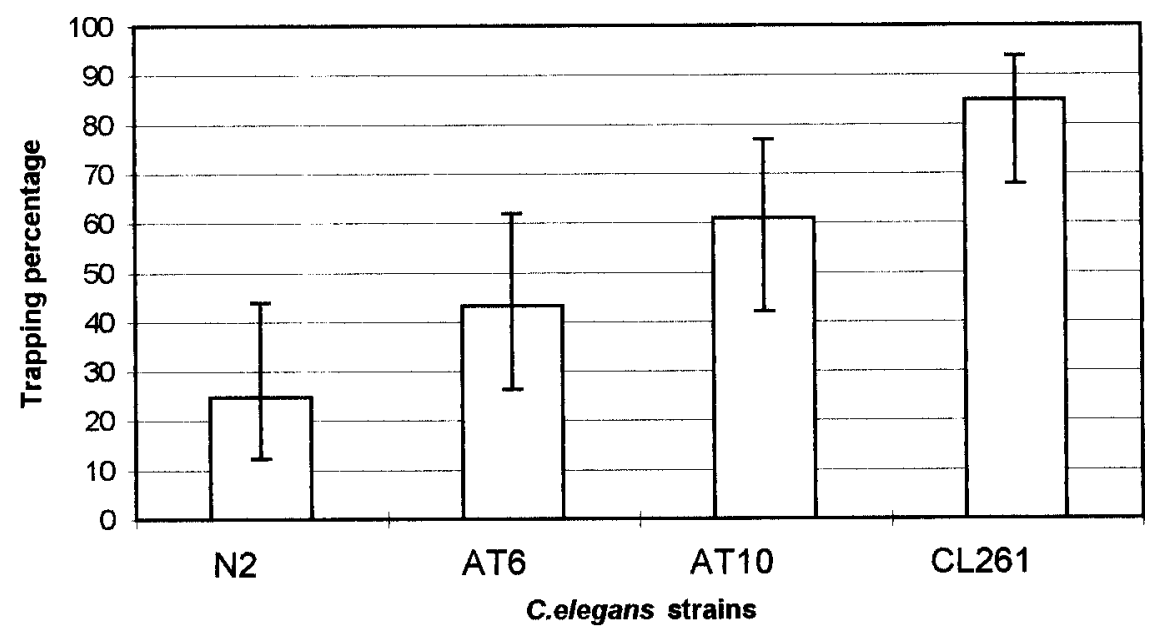

Fig. 2. Mean percentage of wild-type (N2) and different surface mutants of Caenorhabditis elegans trapped by Duddingtonia flagrans FTHO-8 after $24 \mathrm{~h}$ on CMA plates at $25{ }^{\circ} \mathrm{C}$. Bars represent $95 \%$ confidence intervals around the mean $(n=5)$.

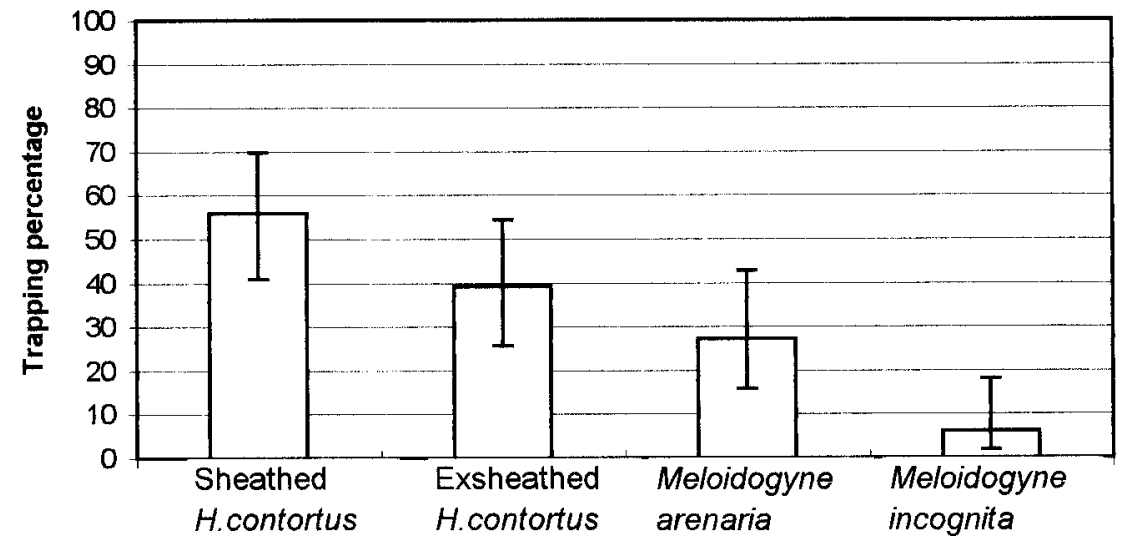

Fig. 3. Mean percentage of sheathed and exsheathed infective Haemonchus contortus and Meloidogyne spp. trapped by Duddingtonia flagrans (FTHO-8) after $24 \mathrm{~h}$ at $25^{\circ} \mathrm{C}$ on CMA. Bars represent $95 \%$ confidence intervals around the mean $(n=3)$.

the wild-type and srf mutants of C. elegans, after $24 \mathrm{~h}$ at $25^{\circ} \mathrm{C}$ recording the following trapping percentages: $0 \cdot 67(0,25 \cdot 89), 4 \cdot 32(0 \cdot 8,19 \cdot 11), 4 \cdot 63(1 \cdot 0$, 9.44) and 25.97 (13.10, 44.95) against N2, AT6, AT10 and CL261, respectively. The trapping percentages of D. flagrans (FTHO-8) against the wildtype and the 3 srf mutants are shown in Fig. 2. The wild-type C. elegans (N2) was less efficiently captured by D. flagrans (FTHO-8) than any of the srf mutants; there were also differences in the percentage of trapped nematodes between each of the srf mutants with increased susceptibility to capture as follows: AT6 < AT10 < CL261.

Cuticle variation and trapping ability on plant and animal parasites

D. flagrans FTHO-8 was consistently more successful in trapping animal and plant-parasitic nematodes than the Arthrobotrys FTHO-3 isolate. In fact, Arthrobotrys trapped less than $2 \%$ of the nematodes under study so only data for D. flagrans FTHO-8 were analysed here. The trapping behaviour of $D$. flagrans FTHO-8 depended on the species of nematode tested $\left(\chi_{3}^{2}=45 \cdot 13, P<0.001\right)$; fewer rootknot nematodes, (Meloidogyne spp.) were trapped than $H$. contortus; and fewer $M$. incognita were trapped than $M$. arenaria (Fig. 3). Although the percentages of sheathed infective larvae of $H$. contortus and T. axei trapped by D. flagrans FTHO8 were higher when compared with their corresponding exsheathed larvae (Figs 3 and 4), no statistical difference was found between them. However, sheathed $T$. circumcincta larvae were more efficiently trapped than exsheathed larvae by both fungi (Fig. 4) Overall, T. circumcincta was more effectively trapped than $T$. axei $\left(\chi_{1}^{2}=36 \cdot 30, P<\right.$ 0.001), D. flagrans FTHO-8 trapped a higher percentage of larvae than Arthrobotrys sp. FTHO-3 $\left(\chi_{1}^{2}=5 \cdot 88, P<0.05\right)$ and sheathed larvae were more effectively trapped than exsheathed larvae $\left(\chi_{1}^{2}=\right.$ $28 \cdot 1, P<0 \cdot 001)$.

\section{CAMBridge JOURNALS}


A

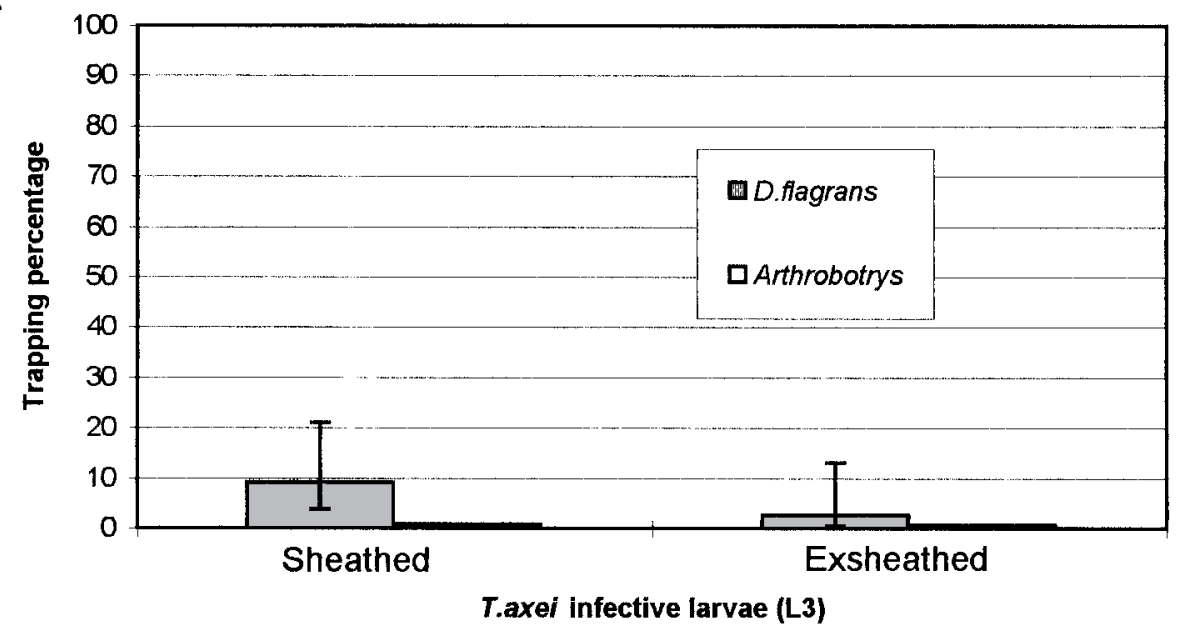

B

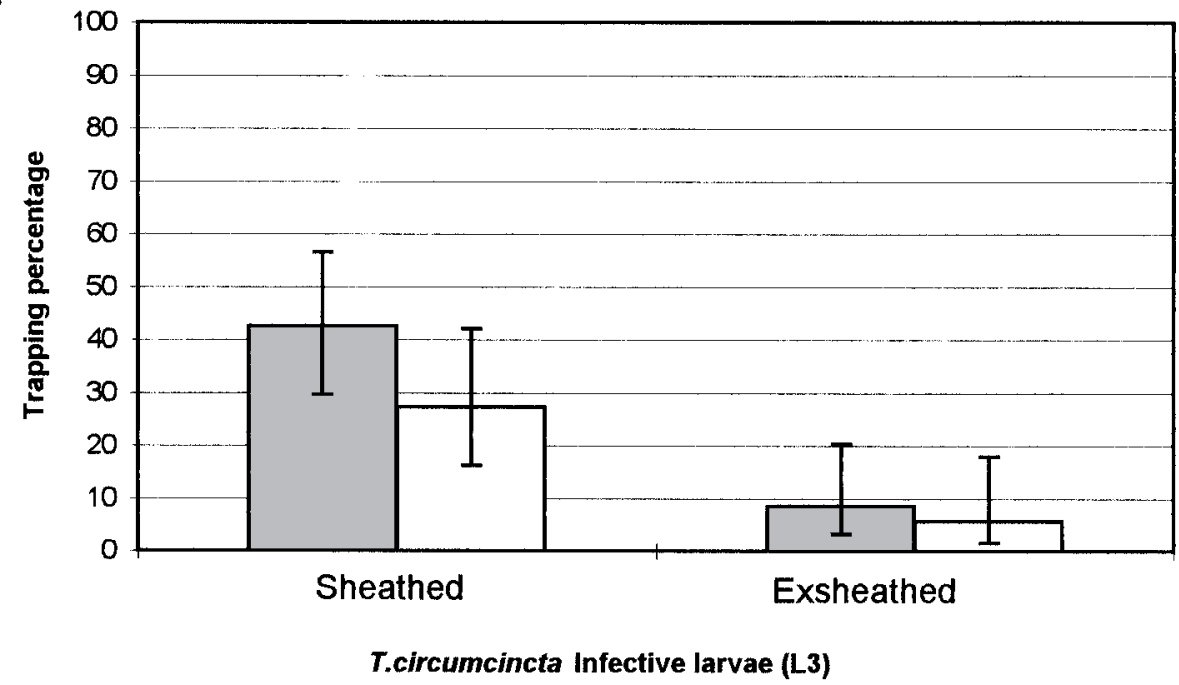

Fig. 4. Mean percentage of Trichostrongylus axei (A) and Teladorsagia circumcincta (B) infective larvae trapped by Duddingtonia flagrans (FTHO-8) and Arthrobotrys sp. (FTHO-3) after 24 h on CMA plates at $25{ }^{\circ} \mathrm{C}$. Bars represent $95 \%$ confidence intervals around the mean $(n=4)$.

\section{DISCUSSION}

Differences found in the motility of the C. elegans population tested did not reflect any relation with the trapping efficiency or in the trap formation by the nematode-trapping fungi. The data reported here clearly demonstrate that the nature of the cuticle is important in determining the ability of trapping fungi to capture nematodes. The different fungi used responded at different rates to the presence of the N2 wild-type $C$. elegans during the first $24 \mathrm{~h}$ whereas all fungi were able to capture this nematode with an equally high efficiency by $60 \mathrm{~h}$. The differences in the ability to capture this nematode were not only observed amongst fungi from different genera, but even between the isolates of $D$. flagrans. This suggests that the molecular recognition in the fungal traps of the different genera, species and even isolates of trapping fungi plays an important role in the capture efficiency of nematodes and interacts with the molecular nature of the nematode cuticle.
Different abilities to capture other species of nematodes have been found with trapping fungi. Morgan et al. (1997) found that Arthrobotrys oligospora, D. flagrans and Monacrosporium megalosporum reduced the population of Heligmosomoides polygyrus 3rdstage infective larvae by less than $5 \%$ after 1 day of interaction and by about 55, 70 and $50 \%$, respectively, by the fourth day. Comparable results were obtained by Galper et al. (1995) who made a comparison of the in vitro predatory activity of a group of nematode-trapping fungi including Monacrosporium sp. and 2 isolates of $A$. oligospora against wild-type $C$. elegans; more than $90 \%$ of nematodes were trapped after $24 \mathrm{~h}$. Other fungal isolates have been found to differ in their ability to capture animal-parasitic nematodes; the in vitro trapping ability of different species of fungi against Trichostrongylus axei and Ostertagia ostertagi at different times was evaluated by Pandey (1973) who found Arthrobotrys spp. had trapped $70 \%$ of the larvae of both nematodes after 3 days. The lowest trapping 
effectiveness after 3 days was shown by some species of Monacrosporium including the following records: $M$. bembicoides, $20 \%$; $M$. cionopaga, $47 \%$; and $M$. ellipsospora, $9 \%$. The low and slow trapping activity characteristic of Monacrosporium sp. in the present experiment is comparable with these results.

Predatory behaviour in A. oligospora, D. flagrans and $M$. megalosporum against $H$. polygyrus has been reported to be nematode density-dependent, with an increase in the predatory activity as larval density rises (Morgan et al. 1997). Moreover, nematode density was found to be important in the capture or infection of Meloidogyne javanica larvae by nematophagous fungi in the soil microcosms, where Hirsutella rhossiliensis showed the greatest densitydependent parasitism, followed by $M$. ellipsosporum and Arthrobotrys dactyloides; the least dependent was found in $A$. oligospora and $M$. cionopagum (Jaffee, Tedford \& Muldoon, 1993). In preliminary tests, a large density of nematodes (5000 per plate) promoted a high trapping activity in all the fungi under study, and these studies suggested that trapping behaviour was density dependent and less effective at low nematode densities. In the present study, we found clear differences in the capture of N2 wild-type by Arthrobotrys when the nematode density increased, but this was not consistent. Increasing the density of the wild-type $C$. elegans produced a strong effect on the trapping response of Arthrobotrys sp. and D. flagrans PF, however, this effect was not seen in D. flagrans FTHO-8 and Monacrosporium sp. We also found that at a low nematode density the Arthrobotrys and the $2 D$. flagrans isolates showed more efficient predatory activity against the AT6 strain than the N2 wildtype. The reason for these differences is unclear but almost certainly involves the interactions between the surface polymers on the traps and the glycocalyx of the nematode cuticle which is thought to involve a lectin-carbohydrate recognition process (Tunlid et al. 1991; Tunlid, Johansson \& Nordbring-Hertz, 1992). Other processes which involve the reorganization of the surface polymer layer and release of enzymes, which in turn lead to the firm binding of the nematode, may also be influential (Tunlid et al. 1992). All 3 srf mutants of C. elegans tested here were more efficiently captured than wildtype N2 by D. flagrans. Politz et al. (1990) have suggested that nematodes have hidden antigenic determinants which, if unmasked by mutagenesis, can be revealed in the cuticle surface. This work suggests that these hidden antigens make the srf mutant nematodes more susceptible to the fungal traps than the wild type.

Throughout all the experiments with plant and animal-parasitic nematodes $D$. flagrans was more effective in capturing nematodes than Arthrobotrys, where, apart from $T$. circumcincta, the number of trapped nematodes was never more than $6 \%$. In particular, the fact that $D$. flagrans trapped $M$. arenaria more efficiently than $M$. incognita suggests that the latter could also possess some masking structures on its cuticle which hide the molecular receptors involved in the trapping process, but which are not present on $M$. arenaria. The observation that Arthrobotrys sp. showed a very low activity against $M$. arenaria and no detectable trapping of $M$. incognita, when compared to D. flagrans, is unclear. However, experiments with $C$. elegans wild-type suggested that at low nematode densities Arthrobotrys produced a smaller number of traps than $D$. flagrans, and this may be due, either to the inability of Arthrobotrys to recognize the elicitors which stimulate trap production, or to far fewer elicitors being produced by these nematodes. The failure of D. flagrans to capture Meloidogyne species reported by Belder \& Jansen (1994) compared with our results suggest that some antigenic variation could be present in different isolates of root-knot nematodes, or even in different isolates of the same species of a nematode-trapping fungus, which could result in a different trapping efficiency. The sheath of infective Trichostrongylids is regarded as a protective layer against the environment, so it is surprising that sheathed $T$. circumcincta were more easily trapped than exsheathed larvae. Stage-specific surface molecules in $H$. contortus have been identified by using monoclonal antibodies; antibodies recognize epitopes which are present in the surface of 2 nd-stage larvae and in the protective sheath of the 3 rd-stage larvae but absent from the L3 cuticle itself (Raleigh, Brandon \& Meeusen, 1996). Such differences could be responsible for a different trapping efficiency in the fungi in the present investigation. Similar results were found by Wharton \& Murray (1990) in the capture of sheathed and exsheathed Trichostrongylus colubriformis by $A$. oligospora; removal of the sheath prevented the capture of infective larvae. In contrast, Timper \& Kaya (1989) reported that the L2 cuticle in entomogenous nematodes can be protected from infection by endoparasitic fungi, $H$. rhossiliensis and Drechmeria coniospora; they found that entomogenous nematodes without L2 cuticle were susceptible to infection by these fungi. The infective stages of some animal-parasitic nematodes, for example $H$. contortus, do not lose their sheath until they have entered into their respective hosts (Summerville, 1954). In fact, the sheath plays an important role in resistance of $H$. contortus infective larvae to proteolytic digestion within the digestive tract (Fetterer \& Rhoads, 1996), thereby endowing this stage with the ability to be infective. Entomopathogenic nematodes such as Steinernematids have been shown to escape nematode trapping fungi by slipping out of their 2nd-stage cuticle (Poinar \& Jansson, 1986). The interaction between the fungus and the nematode cuticle is clearly important and can substantially alter the ability of a fungus to 
capture nematodes, particularly at low densities and in the first $24 \mathrm{~h}$ of interaction. This observation has implications for the selection of isolates to be deployed in the management of nematodes.

This work was supported by IACR-Rothamsted and the Consejo Nacional de Ciencia y Tecnología, México. Authors thank Dr Theresa Stiernagle, Caenorhabditis Genetics Center, Minnesota, USA, for supplying the isolates of C. elegans. The Caenorhabditis Genetics Center is funded by the NIH National Center for Research Resources (NCRR). We also thank Dr Ed Munn from the Babraham Institute, Cambridge, UK, and Dr Bob Coop from the Moredun Institute, Dundee, UK, for supplying the animal-parasitic nematodes, and North Carolina State University for supplying the Meloidogyne sp. IACRRothamsted receives grant-aided support from the Biotechnology and Biological Sciences Research Council of the United Kingdom.

\section{REFERENCES}

BARRON, G. L. (1977). The nematode destroying fungi.

Topics in Mycobiology, no. 1, pp. 1-140. Canadian

Biological Publications Ltd, Canada.

BARTNICKI-GARCIA, S., EREN, J. \& PRAMER, D. (1964).

Carbon dioxide dependent morphogenesis in

Arthrobotrys conoides. Nature, London 204, 804.

BELDER, D. E. \& JANSEN, E. (1994). Capture of plantparasitic nematodes by an adhesive hyphae forming isolate of Arthrobotrys oligospora and some other nematode-trapping fungi. Nematologica 40, 423-437.

BIRD, A. F. \& BIRD, J. (1991). The Structure of Nematodes, 2nd Edn. Academic Press, San Diego.

Boisvenue, R. J., BRANDT, M. C., GALloway, R. B. \& HENDRIX, J. C. (1983). In vitro activity of various anthelmintic compounds against Haemonchus contortus larvae. Veterinary Parasitology 13, 341-347.

DAVIES, K. G. \& DANKS, C. (1992). Interspecific differences in the nematode surface coat between Meloidogyne incognita and $M$. arenaria related to the adhesion of the bacterium Pasteuria penetrans. Parasitology 105, 475-480.

DudDington, C. L. (1951). The ecology of predacious fungi. I. Preliminary survey. Transactions of the British Mycological Society 34, 322-331.

FENWICK, D. W. (1951). A new modification of the McMaster slide for use in potato-root eelworm investigations. Fournal of Helminthology 25, 173-176.

FETTERER, R. H. \& RHOADS, M. L. (1996). The role of the sheath in resistance of Haemonchus contortus infectivestage larvae to proteolytic digestion. Veterinary Parasitology 64, 267-276.

GALPER, S., EDEN, M. L., STIRLING, G. R. \& SMITH, J. L. (1995). Simple screening method for assessing the predacious activity of nematode-trapping fungi. Nematologica 41, 130-140.

genstat 5 Committee (1993). Genstat 5 Release 3 Reference Manual. Clarendon Press, Oxford. GONZALEZ CRUZ, M. E., MENDOZa DE GIVES, P. \& QUIROZ Romero, H. (1998). Comparison of the trapping ability of Arthrobotrys robusta and Monacrosporium gephyropagum on infective larvae of Strongyloides papillosus. Fournal of Helminthology 72, 209-214. Greenhouse, S. W. \& GeIsser, s. (1959). Methods in the analysis of profile data. Psychometrika 24, 95-112.
HOOPER, D. J. (1986). Extraction of nematodes from plant material. In Laboratory Methods for Work with Plant and Soil Nematodes (ed. Southey, J. F.), pp. 51-58. Ministry of Agriculture, Fisheries and Food, London, HMSO.

JAFFEe, A. B., TEDFORD, C. E. \& MULDOON, E. A. (1993). Test for density-dependent parasitism of nematodes by nematode-trapping and endoparasitic fungi.

Biological Control 3, 329-336.

KERRY, B. \& JAFFEE, B. A. (1997). Fungi as biological control agents for plant parasitic nematodes. In The Mycota IV, Environmental and Microbial Relationships (ed. Wicklow, D. T. \& Soderstrom, B.), pp. 203-218. Springer-Verlag, Berlin and Heidelberg.

LINK, C. D., SILVERMAN, M. A., BREEN, M. \& WATT, K. E. (1992). Characterization of Caenorhabditis elegans lectin-binding mutants. Genetics 131, 867-881.

LLERANDi JUAREZ, R. D. \& MENDOZA DE GIVES, P. (1998). Resistance of chlamydospores to the digestive processes of sheep in Mexico. Fournal of Helminthology 8, 155-158.

MAizels, R. M., MEGHJi, M. \& OGILVIE, B. M. (1983). Restricted sets of parasite antigens from the surface of different stages and sexes of the nematode parasite Nippostrongylus brasiliensis. Immunology 38, 107-121.

MENDOZA DE GIVES, P., DAVIES, K. G., MORGAN, M. \& BeHnke, J. M. (1999). Attachment test of Pasteuria penetrans to the cuticle of plant and animal parasitic nematodes, free-living nematodes and srf mutants of Caenorhabditis elegans. Fournal of Helminthology 73, 67-71.

MENDOZA DE GIVES, P., FLORES-CRESPO, J., HERRERARODRIGUEZ, D., LIEBANO-HERNANDEZ, E., VAZQUEZPRATZ, V. M. \& ONTIVEROS-FERNANDEZ, G. E. (1998). Biological control of Haemonchus contortus infective larvae in ovine faeces by administering an oral suspension of Duddingtonia flagrans chlamydospores to sheep. Fournal of Helminthology 72, 343-347.

MENDOZa DE Gives, P., Zavaleta, M. E., HeRRera, R. D. \& QUIROZ, R. H. (1994). In vitro trapping capability of Arthrobotrys spp. on infective larvae of Haemonchus contortus and Nacobbus aberrans. Fournal of Helminthology 68, 223-229.

MORGAN, M., BEHNKe, J. M., LUCAS, A. J. \& PEBERDy, F. J. (1997). In vitro assessment of the influence of nutrition, temperature and larval density on trapping of the infective larvae of Heligmosomoides polygyrus by Arthrobotrys oligospora, Duddingtonia flagrans and Monacrosporium megalosporum. Parasitology 115, 303-310.

NANSEN, P., GRONVOLD, J., HENRIKSEN, S. A. \& WOLSTRUP, J. (1988). Interactions between the predacious fungus Arthrobotrys oligospora and third-stage larvae of a series of animal parasitic nematodes. Veterinary Parasitology 26, 329-337.

NORDBRING-HERTZ, B. \& FRIMAN, E. (1982). A recognition mechanism in the adhesion of nematodes to nematode-trapping fungi. In Lectins-Biology, Biochemistry, Clinical Biochemistry, Vol. II. pp. 83-90. Walter de Gruyter \& Co., Berlin.

NORDBRING-HERTZ, B. \& MATTIASSON, B. (1979). Action of a nematode-trapping fungus shows lectin-mediated host-microorganism interaction. Nature, London 281, $477-479$. 
PANDEY, v. s. (1973). Predatory activity of nematodetrapping fungi against the larvae of Trichostrongylus axei and Ostertagia ostertagi: A possible method of biological control. Fournal of Helminthology 43, 35-48.

Philipp, M., PARKhouse, R. M. E. \& OGILVIE, B. M. (1980). Changing proteins on the surface of a parasitic nematode. Nature, London 287, 538-540.

POINAR, G. O. J. \& JANSSON, H. B. (1986). Infection of Neoplectana and Heterohabditis (Rhabditida: Nematoda) with the predatory fungi Monacrosporium ellipsosporum and Arthrobotrys oligospora Moniliales: Deuteromycetes. Revue de Nematologie 9, 241-244.

POlitz, s. M. \& PHILIPP, M. (1992). Caenorhabditis elegans as a model for parasitic nematodes: A focus on the cuticle. Parasitology Today 8, 6-12.

POLITZ, S. M., PHILIPP, M., ESTEVEZ, M., O’BRIEN, J. P. \& CHIN, J. K. (1990). Genes that can be mutated to unmask hidden antigenic determinants in the cuticle of the nematode Caenorhabditis elegans. Proceedings of the National Academy of Sciences, USA 87, 2901-2905.

RALEigh, J. M., BRANDON, R. M. \& MEEUSEN, E. N. T. (1996). Stage-specific expression of surface molecules by the larval stages of Haemonchus contortus. Parasite Immunology 18, 125-132.

RALEigh, J. M. \& MEEUSEN, E. N. T. (1996).

Developmentally regulated expression of a Haemonchus contortus surface antigen. International Fournal for Parasitology 26, 673-675.

RosenZWeig, D. W. \& ACKROYD, D. (1983). Binding characteristics of lectins involved in the trapping of nematodes by fungi. Applied and Environmental Microbiology 46, 1093-1096.

RosenzWeig, D. W., PREMaChandran, D. \& PRAMER, D. (1985). Role of trap lectins in the specificity of nematode capture by fungi. Canadian Fournal of Microbiology 31, 693-695.
Sharma, S. B. \& DAvies, K. G. (1996). Comparison of two sympatric Pasteuria populations isolated from a tropical vertisol soil. World Fournal of Microbiology and Biotechnology 12, 361-366.

Silverman, M. A., BlaXter, L. M. \& LiNK, D. C. (1997). Biochemical analysis of Caenorhabditis elegans surface mutants. Fournal of Nematology 29, 296-305.

SuMMerville, R. I. (1954). The second ecdysis of infective nematode larvae. Nature, London $\mathbf{1 7 4}$, $751-752$.

TIMPER, P. \& KAYA, K. H. (1989). Role of the second-stage cuticle of entomogenous nematodes in preventing infection by nematophagous fungi. Fournal of Invertebrate Pathology 54, 314-321.

TUNLID, A., JANSSON, H. B. \& NORDBRING-HERTZ, B. (1992). Fungal attachment to nematodes. Mycological Research 96, 401-412.

TUNLID, A., JOHANSSON, T. \& NORDBRING-HERTZ, B. (1991). Surface polymers of nematode-trapping fungus Arthrobotrys oligospora. Fournal of General Microbiology 137, 1231-1240.

weisberg, s. (1985). Applied Linear Regression. Wiley, New York.

WHARTON, D. A. \& MURRAY, D. s. (1990). Carbohydrate/lectin interactions between the nematophagous fungus, Arthrobotrys oligospora, and the infective juveniles of Trichostrongylus colubriformis (Nematoda). Parasitology 101, 101-106.

Williams, D. A. (1982). Extra-binomial variation in logistic linear models. Applied Statistics 31, 144-148.

Wolstrup, J., NANSEN, P., GRonvold, J., HeNRIKSEN, s. A. \& LARSEN, M. (1996). Toward practical biological control of parasitic nematodes in domestic animals. Fournal of Nematology 28, 129-132.

wood, в. w. (1988). The nematode Caenorhabditis elegans. Cold Spring Harbor Laboratory. New York, USA. 